\title{
(STUDI LITERATUR) PENGGUNAAN MODEL MIND MAP PADA PEBELAJARAN GEOGRAFI DI SEKOLAH DASAR
}

\author{
Aina Ansa Zulfa, Muh Husen Arifin, Yona Wahyuningsih \\ Surel: ainaansazulfa@ upi.edu
}

\begin{abstract}
This article discusses the Mind Mapping method that can improve students' ability to be active in class. The purpose of this article is to find out that the Mind Mapping method can increase student activity in the classroom. Activeness here means that the role of students is very influential on learning in the current curriculum, that learning must be student center and the teacher here is only a facilitator. With the use of Mind Mapping, it is hoped that students will not feel bored with memorizing subjects, and with the use of Mind Mapping it will make it easier for students to memorize learning theories. Through mind mapping, students are expected to be able to express their opinions, be interactive, and think imaginatively with the aim of freeing students from memorization that is comfortable for them. Therefore, by using the Mind Mapping method, students can change their habits. Atfirst they only paid attention to the teacher, but now they are required to be more active in each lesson.
\end{abstract}

Keywords: Learning, Method, Mind Mapping

\begin{abstract}
ABSTRAK
Artikel ini membahas tentang metode Mind Mapping yang dapat meningkatkan kemampuan keaktifan siswa di kelas. Tujuan dibuatnya artikel ini ialah untuk mengetahui bahwa metodde Mind Mapping dapat meningkatkan keaktifan siswa di kelas. Keaktifan disini berarti perann siswa yang sangat berpengaruh terhadap pembelajaran di kurikulum sekarang, bahwasanya pembelajaran harus bersifat student center dan guru disini hanay sebagai fasilitator saja. Dengan penggunaan Mind Mapping ini diharapkan siswa tidak merasa bosan dengan mata pelajaran hafalan, dan dengan penggunaan Mind Mapping ini akan mempermudah siswa dalam penghafalan teori pembelajaran. Melalui mind Mapping ini siswa diharapkan mampu untuk menyampaikan pendapat, interaktif, dan berpikir imajinasi dengan tujuan membebaskan siswa dalam penghafalan yang nyaman bagi mereka. Maka dari itu dengan menggunakan metode Mind Mapping ini siswa dapat perubah kebiasaanya yang semulanya mereka hanya memperhatikan guru, namun sekarang mereka dituntut lebih aktif dalam setiap pembelajarannya.
\end{abstract}

Kata Kunci: Pembelajaran, Metode, Mind Mapping

\section{PENDAHULUAN}

Pendidikan bertujuan untuk membenarkan atau mengarahkan tingkah laku manusia agar memperoleh sebuah etika yang baik. Lebih dari itu pendidikan juga marupakan jalan atau jalur untuk mengembangkan kreativitas seseorang guna untuk memposisikan merekka berbaur dalam kehidupan masyarakat.(Haryanto, 2019).

Pendidikan merupakan usaha sadar yang pertama kali dulakukkan oleh kedua orang tua, kemudian lingkungan keluarga, ruang lingkup masyarakat, dan lebih luasnya lagi 
dilingkungan pemerintahan, melalui kegiatan bimbingan, latihan, yang bisa saja dilakukan dimana saja dan kapan saja yang berlaku selama seumur hidup, untuk mempersiapkan tunas bangsa yang nantinya dappat mengikuti dan menikmatinya sebagai peranan dalam hidupnya di masa depan.(Rofifah, 2020) Pendidikan juga merupakan sebuah pengalaman yang terukir atau tersusun atas bentuk sebuah pendidikan resmi, dan non resmi dengan istilah lain formal dan Non-formal yang diperoleh didalam maupun diluar sekolah untuk emnyapkan peserta dalam peranannya nanti di masa depan. Ujar kata (Redja Mudyahardjo, 2014:11).

Seiring berjalannya waktu, sebuah system pendidikan di Indonesia ini berubah ubah, yang pada mulanya seperti yang diketahui dimana Kurikulum 1947 arah pendidikannya lebih bersifat politis, 1952 yang mulai merinci mata pelajarannya, 1964 fokus pada SD sebagai jenjang pembekalan masyarakat. Sedikit lebih jauh pada tahun 2004 disini system pendidikannya KBK dan mulai adanya KTSP di tahun 2006, dan disempurnakkan lagi menjadi kurikulum 2013 yang digunakkan sebagai peraturan pembelajaran saat ini. (ruliansyah anwar).

Adapun problema yang sering dijumpai bahwasanya kebanyakan guru yang beradadi daerah 3T dan pangkatnya senior, justru lebih banyak menggunakan model-model lama yang mereka gunakkan. Di antaranya menggunakan KTSP sebagai acauan model pembelajarannya, namun tetap materi yang digunakan ialah materi yang ada dalam buku tema siswa. Salahnya dimana? Yaitu tidak tepatnya penggunaan model dengan materi yang disampaikannya.

Oleh karena itu, siswa menjadi timbul kebingungan saat pembelajaran sedang berlangsung. Adanya materi yang digunakkan pada buku tema, berarti kita juga perlu menggunakan model-model yang belaku pada Kurikulum 2013 ini. Sehingga anak tidak mudah bosa dalam belajar yang mana guru hanya menggunakan metode ceramah saja dalam penyampaian materi, tanpa adanya kegiatan eksplorasi pada keberlangsungan belajar mengajarnya. Namun disisi lain juga alas an yang menjadi mereka haya menggunakan kurikulum lama ini ialah daerah sekolah tersebut termasuk kedalam $3 \mathrm{~T}$ yang terkadang mengakses bahan ajar, dan mencaru update an pendidikan sekarang yang menjadi hambatan mereka untuk mengikuti aturan pemerintah sekarang. Dengan demikian kita sebagai calon guru perlu melakukkan terobosan bagaimana keefektifan sebuah model pembelajaran yang dapat disesuaikan dengan keinginan siswa serta tidak menyalahi aturan pendidikannya salahsatunya dengan menggunakan metode Mind Map pada pembelajaran IPS.

Pembelajaran ialah suatu kegiatan yang mengarahkan manusia kea rah yang lebih baik. Dalam kata lain perolehan pembelajaran berawal dari lingkungan keluarga, masyarakat dan 
wilayah tertentu dengan cakupan daerah itu sendiri guna untuk mempersiapkan diri dala kehidupan yang akan dihadapi di masa depan nanti. Belajar adalah prosesyang kompleks yang terjadi pada setiap orang dan itu akan berlaku seumur hidup . belajar dapat terjadi dimana saja, seperti di rumah, sekolah, tempat kerja, tempat ibadah dan berlangsung dengan cara apa saja, siapa saja, dan bagaimana pun itu bisa terjadi. Adapun tanda dari seseorang itu sudah belajar ialah dilihat dari tingkah lakunya yang berubah, mulai dari keterampilan, pengetahuan ataupun itu sikap.

Adapun pengertian model mind mapping ialah model dimana model ini menonjolkan tulisan dan pengoordinasian sebuah materi yang akan dibahas.dalam kata lain Mind mapping ini adalam model yang mempelajari konsep atau teknik mengingat sasuatu dengan bantuan mind map (menggunakan peta konsep, pencatatan materi pembelajaran yang dituangkan pada bentuk bagan, symbol, kode dan warna yang berhubungan satu sama lain) sehingga kedua bagian otak manusai dapat digunakan secara maksimal dimana hal ini membantu dalam proses pembelajarannya dan diharapkan mendapatkan sebuah ide yang bermacam-macam.

Mind Mapping merupakan Pikiran Peta sebagai alat yang berguna diungkapkan oleh siswa pikiran mereka. Siswa ditanya buatlah peta pikiran penjelasan yang diberikan oleh guru. dalam hal ini guru memberikan kebebasan berpikir siswa dan siswa dapat dengan bebas memutuskan bagaimana solusi logis dan masuk akal.

Kemudian siswa hadir hasil pemikiran mereka. Sebuah pelajaran tampilan peta pikiran dapat membantu anak-anak mengingat rasio bicara gunakan daftar, dan memori ditingkatkan menjadi 32 Tindakan pencegahan lain untuk digunakan bantuan mind map yaitu pelatihan otak melihat keseluruhan pada saat yang sama dalam detail dan Ini terjadi dalam integrasi antara logika Dan imajinasi. (Zahro, Degeng and Mudiono, 2018).

\section{METODE PENELITIAN}

Jenis metode penyelidikan yang digunakan ini ialah dengan menggunakan metode kualitatif dimana menggunakan pernyataan-pernyataan yang sudah ada dengan mengandalkan kepustakaan dan tulisan sebelumnya (studi literature).

\section{HASIL PENELITIAN DAN PEMBAHASAN}

Dari penelitian yang dikuasai oleh peneliti ialah maka didapatkan terkait hasil mengenai metode pembelajaran Mind Mapping dimana pada metode ini siswa lebih aktif dan mampu berpikir apa saja inti sari dari perolehan hasil belajarnya. Analisis ini dilakukan dengan cara Non-interaktif dimana hanya menggunakan pencarian dan terus mencari kajian yang berkenaan dengn model pembelajaran Mind Mapping 
pada literature yang sudah ada sebelumnya.

Metode mind mapping ini memudahkan siswa untuk menghafal teori pembelajaran. Menurut Asrori pada penelitiannya menyatakkan bahwa penerapan metode Mind Mapping ini menghasilkan peningkatan belajar siswa menjadi naik, semakin baik, menghasilkan nilai rata-rata yang meningkat serta pembelajaran bisa dikendalikan kondusif dan terarah. (Studi et al., 2014).

Menurut Buzan \& Barry (2004) mengatakan bahwa, melalui mind mapping (peta pikiran), materi dapat dibuat lebih ringkas meskipun objeknya luas dan dapat mengemat waktu dalam menjelaskan secara keseluruhan, karena hanya menjelaskan antar bagiannya saja. Disitu dilihat ternyata siswa bisa lebih berpikir kreatif,, imajinatif dan melatih menympukan informasi yang lebih efektif. (Tri Fadhila, 2017).

Pemanfaatan mind mapping ini akan mendapatkan sebuah keuntungan bagi siswa, diantaranya: pembelajaran bisa dilihat dengan cara keseluruhan; (2) melatih daya piki dalam bentuk initi keterkatian, dan perbandingan dalam materi, (3) memudahkan mengeksplor informasi baru (4) dapat berulangkali di ingat (5) membantu daya pikir konsentrasi, informasi dapat terlihat jelas (6) keterkaitan antara pokok pikiran akan terlihat (7) mudah diingat, dan (8) mempermudah dalam memberikan peran aktif pada siswa. (Basuki, 2020)
Adapun penerapan metode Mind Mapping diantaranya sebagai berikut: (1) guru perlu menyampaikan KD yang perlu dicapaioleh siswa, (2) guru menjabarkan konsep yang akan dipelajari, (3) menintruksikan siswa untuk membuat mind mapping dari materi letak geografis Indonesia, dan yang terakhir (4) guru membahas dan menyimpulkan materi. (Nazarrotin, Resnani and Hasnawati, 2018).

Karakteristik dari metode Mind Mapping ini ialah dalam isinya akan menghasilkan sebuah catatan atau sebuah ide pokok pada sebuah materi, maka dari itu mind mapping ini sebuah runtutuan ide pokok yang disajikan menjadi peta bergaris yang berwarna dengan beraturan supaya mudah diingat yang selaras dengan kerja alami otak. (Nazarrotin, Resnani and Hasnawati, 2018).

Pemetaan pikiran memungkinkan otak manusia untuk dieksplorasi dan bekerja dengan baik Menurut fungsinya. Otak manusia terdiri dari otak kanan dan otak kiri. Ada Dalam mind mapping, dua sistem otak diaktifkan secara bersamaan sesuai dengan bagiannya. Kombinasi warna, gambar, dan cabang akan merangsang secara visual. Melewati Oleh karena itu, informasi dari mind map mudah diingat (Buzan, 2011). Dari deskripsi Dari sini dapat disimpulkan bahwa peta pikiran adalah sejenis Dapat membantu siswa mendeskripsikan ide menulis dalam bentuk cabang dengan berbagai imajinasi kreatif.(Subakti and Handayani, 2020). 
Adapun tahapan dalam pembuatan mind mapping ini sebagai berikut: (1) diawali dengan bentuk kertas yang landscape dengan memulai tulisannya dari bangian tengah, (2) menggunakan bentuk atau foto yang sangat menarik agar mudah di ingat dalam berimajinasi, (3) gunakanlah warna sebagai penghubung satu sama lain ide pokok pikiran, (4) hubungkan inti pokok pikiran dengan beberapa cabang (5) gunakan bentuk-bentuk yang sesuai dengan keinginan agar kemampuan berpikirnya di buat dengan semaunya saja. (Buzan, 2005).

Dibalik metode Mind Mapping ternyata mengandung beberapa kelebihan untuk menjadikan siswa lebih bersemangat dalam belajarnya, dimana kemampuan berpikir imajinatifnya berkembang. Hal tersebut juga sesuai dengan hasil penelitian oleh (Ria Satini, 2016) bahwa penggunaan metode mind mapping ini dapat memotivasi siswa dalam mengembangkan pokok pikiran, imajinatif, dan kreatif. (Nazarrotin, Resnani and Hasnawati, 2018). Dalam pembelajaran IPS juga siswa mampu menemukan gagasan pikiran letak geografis Indonesia beserta isinya, yang mana diapit oleh dua benua dan dua samudra dan juga sebagai jalur perdagangan dunia.

Adanya hasil pembelajaran yang dikatakan kurang dalam belajar ini, bisa saja disebabkan oleh dua hal, baik dari gurunya, maupun siswa itu sendiri. Penyebab yang bisa saja muncul saat pembelajaran ini diantaranya: (1) siswa belajar secara mandiri, ataupun siswa tersebut kurang percaya diri dalam menyampaikan pendapat. bilamana berasal dari guru, metode pembelajaran siswnaya kurang berfariatif, serta guru hanyaa memberikan catatan biasa saja, kemungkinan guru masih menggunakan techer center, sedangnkan yang diharuskan pada masa kini ialah student center. Dari sini ia berpendapat bahwasanya guru perlu melakukan pembawaan belajar yang enyenangkan untuk di plikasikan pada kegiatan belajar mengajar denganc ara pengaplikasian metode Mind Mapping ini. Model Mind Mapping ini dikembangkan metode yang sangat efektif untuk mengembangkan point penting dalam penyampaian pembelajaran dengan melalui rangkaian seperti peta konsep yang berasal dari pendapat Tony Buzan. (Manullang and Silaban, 2020).

Penerapan kolaborasi model Mind Mapping dengan model lain sisw amampu meningkatkan hasil pembelajaran yang sangat signifikan. Maka dari itu pembelajaran metode Mind Mapping ini sangat sesuai dengan hasil minat belajar siswa di kelas. Karena penggunaan metode Mind Mapping ini siswa benar-benar melakukan kegiatan yang mandiri ataupun kelompok, sehingga ide gagasan yang didapat dan diterima oleh anak, benar-benar real dari hasil pemikiran merka, sehingga mempermudah dalam penghafalan maupun pembelajaran. (Rozhana and Fidiastuti, 2017). 
Adapun mind mapping ini diawali dengan mengintruksikan siswa untuk menjawab pertanyaan dalam LKPD secaara berkelompok maupun individu, kemudian untuk penyampaiannya, nanti mereka memaparkan hasil diskusi di depan kelas dengan penilaian langsung dari guru. Dari hasil yang telah dipaparkan, siswa mampu memiliki rasa tanggung jawab ataas apa yang telah mereka kerjakan. Oleh karena itu siswa akan memiliki daya pikir bahwasanya apa yang mereka dan lakukan, dari situ mereka sangat perlu mempertanggungjawabkan hasil pengerjaanya. (Florida, López and Pocomucha, 2012).

Penggunaan model pembelajaran mind map dapat digunakan untuk berusaha untuk meningkatkan keterampilan, kemampuan dan hasil belajar siswa. Model ini sangat menarik karena semua siswa berpartisipasi dalam produksi peta pikiran. Siswa akan berkreasi dengan ide enarik untuk digaris bawahi dalam proses pembelajaran menggunakan model mind map agar merangsang munculnya kreativitas siswa. Dengan menggunakan model peta pikiran dibandingkan dengan menggunakan metode ini, keterampilan kreatif siswa telah meningkat pesat ceramah yang masih sering digunakan guru. (Wulandari, Mawardi and Wardani, 2019).

Penggunaan model peta pikiran memiliki dampak pada penelitian sosial dan hasil belajar sekolah dasar. Ini dilihat dari data setelah aplikasi model pembelajaran peta pikiran, hasil belajar siswa bisa dikatakan meningkat dari 11 sampel total 75,09 dari yang sebelumnya 53.57. Dilihat dari data tersebut, ada peningkatan yang signifikan Signifikansi sama dengan 21,52 atau rasio hasil tingkat belajar siswa naik menjadi 40,17\%. Artinya penerapan model pembelajaran mind map ini pengaruh positif terhadap hasil belajar penelitian sosial murid. Rekomendasi bagi peneliti untuk dilakukan penelitian serupa untuk meningkatkan jumlah sampel penelitian untuk mempelajari hasil digunakan sebagai bahan kontras Informasi tambahan tentang dampak mental pemetaan hasil belajar penelitian sosial. di samping itu dengan jumlah data yang digunakan, itu akan dapatkan data yang lebih objektif dan berikan gambar lebih jelas.

\section{Pembahasan}

Letak geografis merupakan letak suatu kawasan yang dilihat dari sudut kenyataan di permukaan bumi, atau perbandingan dengan daerah lain. Letak geografis itu ditentukan oleh letak astronomis dan geologisnya. Secara geografis, Indonesia ini terletak di antara 2 samudera besar dunia, yaitu samudra hindian dan fasifik, kemudian tidak hanya diapit 2 samudra saja, melainkan Indonesia ini juag diapit oleh 2 benua, yaitu benua asia, dan benua Australia, dan pada pertemuan dua rangkaian pegnungan yaitu sirkum pasifik dan sirkum mediterania. Indonesia juga merupakan Negara kelupauan yang terd iri atas dari ribuan pulau dan posisi 
wilayah yangbamat strategis. Hal ini memiliki keuntungan bagi Indonesia karena berbeda dengan Negara yang lain dari letaknya ini. (Sugiyono, 2016)

Keterkaitannya dengan pembelajaran menggunakan metode Mind Mapping ini dimana salah satunya letak geografis Indonesia yang sebagai inti judul yang akan memaparkan beberapa didalamnya, diantaranya menjadi subjudul, contohnya 2 benua dan 2 samudranya, seta enguraikan isi-isi dari subjudulnya yang mana akan diletakkan di bagian paling luarnya. Maka dari itu metode Mind Mapping ini sangat mempermudah pembelajaran hafalan seperti pada mata pelajaran IPS ini.

\section{SIMPULAN}

Dari pemaparan di atas, disimpulkan bahwasanya penggunaan metode Mind Mapping ini akan memberikan stimulus terhadap siswa supaya mereka lebih aktif selama pembelajaran berlangsung. Melalui Mind Mapping ini siswa mampu berfikir dengan imajinasinya sendiri bagaimana cara penghafalan sebuah materi teerhadap kenyamanan mereka.

\section{DAFTAR RUJUKAN}

Basuki, A. 2020. Pemanfaatan Mind Mapping Dalam Pembelajaran. Jurnal Lingkungan Widyaiswara, 07(02), pp. 18-29.

Haryanto. 2019. Pengertian Pendidikan. Universal Pendidikan, (april 2017), pp. 8-
22. Available at: https://unpendidikan.blogspot.co m/2019/02/pengertian-pend id ika n.html.

Manullang, M. and Silaban, P. J. 2020. Penerapan Model Pembelajaran Mind Mapping Untuk Meningkatkan Hasil Bealajar Siswa pada Tema Daerah Tempat Tinggalku Di Kelas IV SD Negeri 060914 Medan Sunggal Tahun Pembelajaran 2018/2019. Ilmiah Aquinas, 3(1), pp. 110-129.

Nazarrotin, I., Resnani and Hasnawati. 2018. Pengaruh Metode Mind Mapping Terhadap Kemampuan Menulis Karangan Narasi. Jurnal Riset Pendidikan Dasar, 1(1), pp. 15-20.

Rofifah, D. 2020. Hakikat Pendidikan. Paper Knowledge . Toward a Media History of Documents, pp. 12-26.

Subakti, H. and Handayani, E. S. 2020. Pengembangan Menulis Cerita Pendek Kearifan Lokal Menggunakan Model Mind Mapping Siswa SD Kota Samarinda. Jurnal Serambi Ilmu, 21(2), pp. 171-184. doi: 10.32672/si.v21i2.1941.

Wulandari, F. A., Mawardi, M. and Wardani, K. W. 2019. Peningkatan Keterampilan Berpikir Kreatif Siswa Kelas 5 Menggunakan Model Mind Mapping. Jurnal Ilmiah Sekolah Dasar, 3(1), p. 10. doi: 10.23887/jisd.v3i1.17174. 